\title{
BMJ
}

\section{Amateur boxing and risk of chronic traumatic brain injury: systematic review of observational studies}

\author{
Mike Loosemore, lead sports physician, ${ }^{1}$ Charles H Knowles, clinical senior lecturer and honorary consultant \\ surgeon, ${ }^{2}$ Greg P Whyte, professor of sport and exercise science ${ }^{3}$
}

${ }^{1}$ English Institute of Sport, London Region, Olympic Medical Institute, Northwick Park Hospital, Harrow HA1 3UJ

${ }^{2}$ Barts and the London NHS Trust and the Homerton University NHS Foundation Trust, Centre for Academic Surgery, Royal London Hospital, London E1 1BB

${ }^{3}$ Research Institute for Sport and Exercise Sciences, Liverpool John Moores University

Correspondence to: $\mathrm{M}$ Loosemore mike.loosemore@eis2win.co.uk

do:10.1136/bmj.39342.690220.55

\section{ABSTRACT}

Objective To evaluate the risk of chronic traumatic brain injury from amateur boxing

Setting Secondary research performed by combination of sport physicians and clinical academics.

Design, data sources, and methods Systematic review of observational studies in which chronic traumatic brain injury was defined as any abnormality on clinical neurological examination, psychometric testing, neuroimaging studies, and electroencephalography. Studies were identified through database (1950 to date) and bibliographic searches without language restrictions. Two reviewers extracted study characteristics, quality, and data, with adherence to a protocol developed from a widely recommended method for systematic review of observational studies (MOOSE).

Results 36 papers had relevant extractable data (from a detailed evaluation of 93 studies of 943 identified from the initial search). Quality of evidence was generally poor. The best quality studies were those with a cohort design and those that used psychometric tests. These yielded the most negative results: only four of 17 (24\%) better quality studies found any indication of chronic traumatic brain injury in a minority of boxers studied.

Conclusion There is no strong evidence to associate chronic traumatic brain injury with amateur boxing.

\section{INTRODUCTION}

In light of evidence of acute and chronic injuries associated with boxing, the British Medical Association (BMA) has passed a series of resolutions at its annual representative meetings calling for boxing to be made illegal. ${ }^{12}$ The latest report from the BMA Board of Science Working Party on Boxing (now disbanded), published as a briefing paper, continues to campaign for a complete ban on boxing (amateur and professional), mainly because of the purported risk of cumulative brain injury (chronic traumatic brain injury). ${ }^{2}$ Severe acute injuries in boxing (including those resulting in fatality), however, are relatively rare compared with other sports, even when professional and amateur boxing are grouped together. $^{3-5}$

A series of important changes in rules and equipment aimed at improving the safety of boxing have been gradually introduced by boxing authorities since the early 20th century. ${ }^{67}$ Whether such changes have improved safety remains contentious. The box shows changes relevant in amateur boxing. On the basis of published data available at the time, the BMA 2001 report acknowledged that the evidence for chronic traumatic brain injury in amateur boxing was "far less clear cut" than in professional boxing. ${ }^{1}$ There have been several publications since this BMA report that have continued to examine the link between boxing, including the amateur sport, and chronic traumatic brain injury. ${ }^{\mathrm{w} 1 \mathrm{w} 3 \mathrm{w} 4}$

We carried out a systematic review to determine whether amateur boxing leads to chronic traumatic brain injury. We did not consider professional boxing, the incidence of acute injuries, or the moral or legal arguments regarding the sport. A problem with

\section{Changes in rules and equipment in amateur boxing}

1906 - Requirement for a medical examination before the contest

1947- Referees allowed in the ring

1950- Boxing medicals and medical cards introduced with imposition of mandatory suspensions for certain injuries. Doctor must be present at ring side

1962- Establishment of the Medical Commission of the Amateur Boxing Association (ABA)

1964- Introduction of the "standing 8" count

1972 - First publication of Medical Aspects of Amateur Boxing

1984- Head guards introduced for the Los Angeles Olympics

1992- Computerised scoring system introduced at the Barcelona Olympics

1996- Structure of the bouts changed from three rounds of three minutes to four rounds of two minutes

2000- Introduction of the "outclassed" rule (Sydney Olympics): bout stopped automatically if one boxer leads the other by 20 points in any but the final round

2002- Ringside physician regulations changed to include suitably trained paramedics present when the doctor is not trained or equipped for resuscitation (Medical Aspects of Boxing, 2002) 


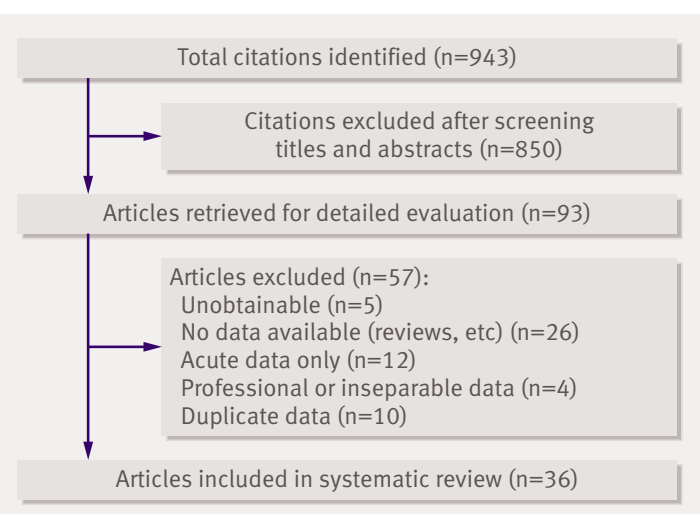

Study selection process for systematic review of chronic brain injury in amateur boxing

performing such a review is the absence of any clear definition of chronic traumatic brain injury. Historically, the first description of a link between boxing and cerebral dysfunction was that of Martland, who described "punch drunk" (although this was actually based on cases described to him by promoters). ${ }^{8}$ This extreme form of injury, perhaps partially encompassed by the current term "chronic traumatic brain encephalopathy" is rare. We clearly needed to consider much more subtle indicators that may be surrogate markers of chronic traumatic brain injury. In the absence of any ideal standards for this, we took the lowest thresholds - that is, any consistent change in the results of neurological examination, brain imaging, psychometric testing, electroencephalography, including a few other relevant studies for completion. We included studies of amateur boxers (including military and police), with the intervention (exposure) being participation in the sport and from which we could extract data.

\section{METHODS}

Though the quality and heterogeneity of available data meant that we could not undertake a meta-analysis, we have adhered as far as possible to the QUOROM statement for systematic reviews. ${ }^{10}$ Because all included studies were observational in design, we also adhered to a protocol developed from a widely recommended method for systematic review/metaanalysis of observational studies (MOOSE). ${ }^{11}$

\section{Search strategy}

Two authors (ML (initial search) and CK (final arbitrator in selection)) carried out a comprehensive search of the literature using Medline and Premedline 1950 to December 2006, Embase, Evidence Based Medicine (EBM) reviews (including the Cochrane database of systematic reviews and the Cochrane central register of controlled trials), and the SPORTDiscus database. The only search term used was "boxing" because of the still manageable number of retrieved titles. In addition, MeSH terms were "("Boxing/adverse effects" OR "Boxing/injuries" OR "Boxing/mortality" OR
"Boxing/physiology" OR "Boxing/psychology"[$\mathrm{MeSH}]$ ) * ("Boxing/adverse effects" OR "Boxing/injuries" OR "Boxing/mortality" OR "Boxing/ physiology" OR "Boxing/psychology"). We hand searched and cross referenced the bibliographies of relevant papers and three books. Two authors were contacted, and one further reference was provided by a reviewer.

\section{Selection}

The figure outlines the study selection process. We included all studies from which we could extract data on outcomes, regardless of study design. We had no language restrictions, though papers were reviewed in detail only when the English title or abstract indicated the likelihood of relevant data. Abstracts and unpublished studies were not included. We also excluded papers with data from amateurs and professionals combined, unless we could separate the data, and those containing duplicate data from a prior publication by the same group.

\section{Assessment of study quality}

We assessed all manuscripts that met the selection criteria for quality. We defined quality as confidence that the study design, conduct, and analysis minimalised bias in the estimation of effect of the risk factor on the outcome measures. Quality assessment was based on published checklists produced to evaluate epidemiological studies that assess potential links between exposures to risk factors and harm. ${ }^{1112}$ This assessment in general reflected the level of evidence on the basis of the established hierarchy of observational studies. ${ }^{12}$ Because the review included several types of observational study ranging from cohort to case series, we modified checklists to include six measures in total that best (although not universally) applied across study types: prospective study design, groups comparable on all important confounding factors, outcome assessed blind to exposure status, follow-up long enough for outcomes to occur (defined as over one year), relation between outcome and exposure appropriately measured, and appropriate statistical analyses used.

\section{Data extraction and synthesis}

ML extracted data, which were checked by CK. As far as possible, we obtained numerical data, though outcome measures were largely categorical in case series (proportions of participants with positive findings) or expressed as group differences in controlled studies. No quantitative data synthesis was performed. Exposure times were collected and expressed as median or mean number of bouts. Accepting that exposure to injury relates to quality, quantity, and length of bouts, we also included the type (level) of boxing where this was recorded. In cohort studies, exposure was presented as length of follow-up in years as well as number of bouts during the study period. 
RESULTS

Literature identification, study design, and quality

We identified 943 citations on the basis of initial search terms, of which we selected 36 articles for the systematic review (from 93 retrieved for detailed evaluation, see figure). ${ }^{\text {w1-w36 }}$ Most exclusions were because there were no original data $(n=26)$ or data were on acute injuries only $(n=12)$ or were duplicate data $(n=10)$. We excluded four studies because we could not separate data from amateur and professional boxers, including one often cited paper. ${ }^{13}$ Five foreign case series from 1959-68 were irretrievable (although these would not necessarily have been included). Of the 36 selected, 16 evaluated findings from psychometric tests, 11 from brain imaging, 14 from electroencephalography, and 12 from neurological examination, with several including more than one outcome measure (63 methods in all). We included four cohort studies, four controlled before and after studies, and 11 case-control studies, with the remainder $(n=17)$ being case series (six of which were prospective - that is, before and after studies in which the cases acted as their own controls).

Overall quality was poor (median score $2 / 6$, range 0-6) (table 1). Table 2 shows the characteristics of studies and table 3 the main results. All are tabulated by quality followed by time since publication - that is, most recent first (in some instances, some studies had different designs or quality and numbers of participants for different outcome measures so we then included the best quality in table 1). We have summarised results for the main outcome measures below in order of general quality.

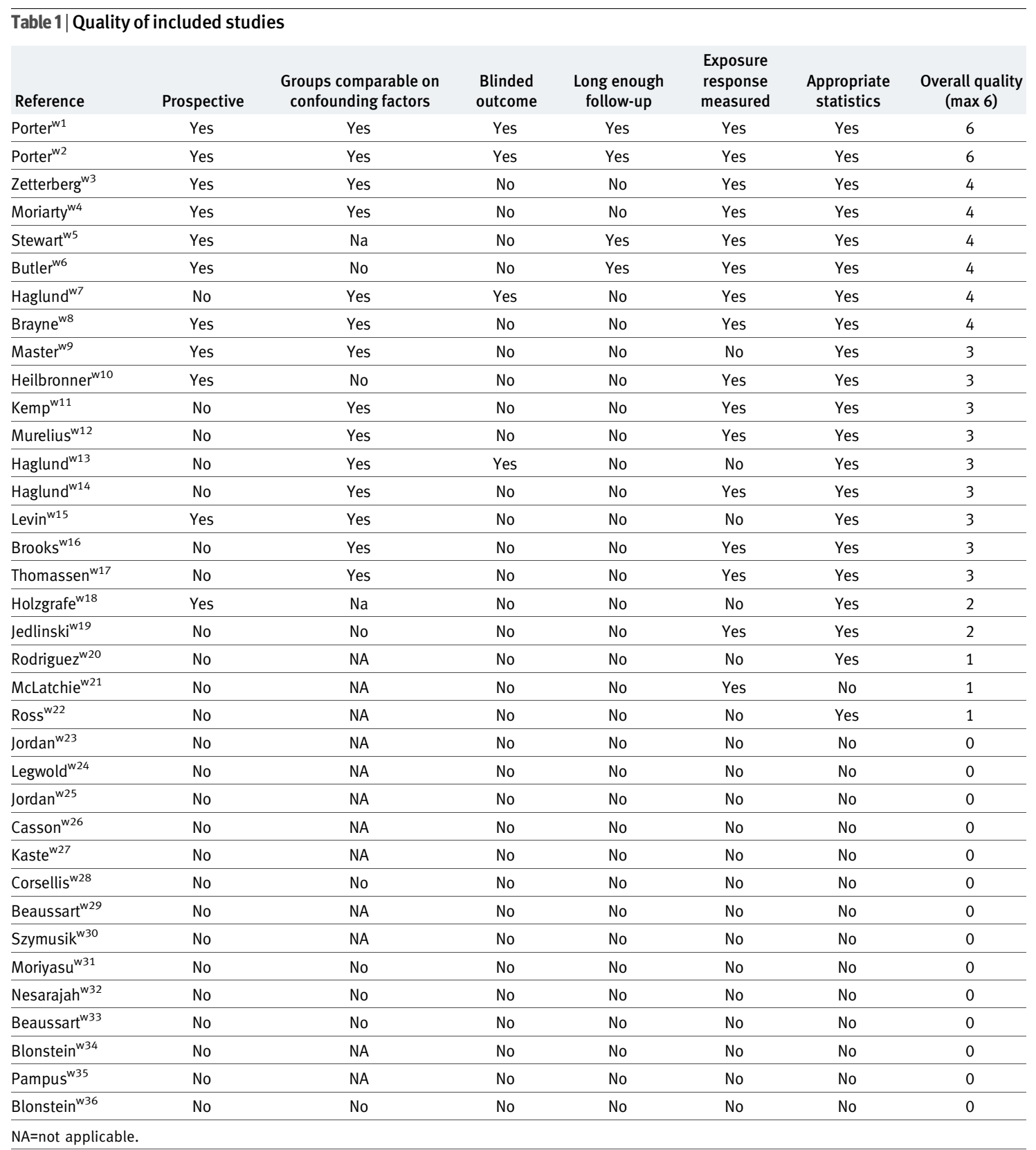


Table $2 \mid$ Characteristics of included studies

\begin{tabular}{|c|c|c|c|c|c|c|c|}
\hline Reference & Study design & $\begin{array}{l}\text { Type of boxing, duration of } \\
\text { follow-up, No of bouts } \\
\text { (mean unless stated) }\end{array}$ & Outcome measures used & $\begin{array}{l}\text { No of } \\
\text { cases }\end{array}$ & $\begin{array}{l}\text { No of } \\
\text { controls }\end{array}$ & $\begin{array}{l}\text { Selection of cases } \\
\text { and controls }\end{array}$ & $\begin{array}{l}\text { Methods used to control } \\
\text { for confounding (when } \\
\text { applicable) }\end{array}$ \\
\hline Porter $^{w 1}$ & Cohort & Club, 9 years, 80 & Psychometric & 20 & 20 & Random & $\begin{array}{l}\text { Age, geographical, sex, } \\
\text { socioeconomic status }\end{array}$ \\
\hline Porterw2 $^{\text {w2 }}$ & Cohort & Club, 2 years, 50 & Psychometric & 20 & 20 & Random & $\begin{array}{l}\text { Age, geographical, sex, } \\
\text { socioeconomic status }\end{array}$ \\
\hline Zetterberg $^{\text {w3 }}$ & Controlled before-after & NS, 3 months, 1 & $\begin{array}{l}\text { Cerebrospinal fluid } \\
\text { biochemistry }\end{array}$ & 14 & 10 & NS & Age, sex \\
\hline Moriarty $^{\text {w4 }}$ & Controlled before-after & Club, 7 days, $1-3$ & Psychometric & 85 & 30 & 1 tournament & Age, sex, education \\
\hline Stewart ${ }^{\mathrm{w} 5}$ & Case series before-after & Club, 2 years, 0->11 & $\begin{array}{l}\text { Psychometric, EEG, Brain } \\
\text { evoked potentials }\end{array}$ & 369 & 0 & Invitation & $\begin{array}{l}\text { Before and after (that is, act } \\
\text { as own controls) }\end{array}$ \\
\hline Butler $^{\mathrm{w6}}$ & Cohort & Club, 2 years, 4 & Psychometric & 86 & 78 & Invitation & Age, sex \\
\hline Haglund $^{\text {w7 }}$ & Case-control & Club, NA, 28 (estimate) & $\mathrm{CT}, \mathrm{MRI}$ & 47 & 50 & Random & Age \\
\hline Brayne $^{\text {w8 }}$ & Controlled before-after & NS, 2 hours, 1 & Creatine kinase BB & 16 & 16 & Invitation & Age, sex \\
\hline Master"w9 & Controlled before-after & Club, 1 bout, 1 & Psychometric & 38 & 28 & Random & Age, sex, education, weight \\
\hline Heilbronner $^{\text {w10 }}$ & Case series before-after & NS, 5 min, 1 bout & Psychometric & 28 & 0 & Invitation & $\begin{array}{l}\text { Before and after (that is, act } \\
\text { as own controls) }\end{array}$ \\
\hline Kemp ${ }^{\text {w11 }}$ & Case-control & Military, NA, 40 (median) & Psychometric, SPECT & 34 & 34 & Invitation & Age, sex \\
\hline Murelius $^{\mathrm{w} 12}$ & Case-control & Club, NA, 28 (estimate) & Psychometric & 50 & 50 & Random & Age, education, sex \\
\hline Haglund $^{\text {w13 }}$ & Case-control & Club, NA, 28 (estimate) & $\begin{array}{l}\text { Neurological, } \\
\text { Psychometric, Pt MAO }\end{array}$ & 50 & 50 & Random & Age, education, sex \\
\hline Haglund $^{\text {w14 }}$ & Case-control & Club, NA, 28 (estimate) & $\begin{array}{l}\text { EEG, brain evoked } \\
\text { potentials }\end{array}$ & 50 & 50 & Random & Age, education, sex \\
\hline Levin $^{\text {w15 }}$ & Cohort & Club, 0.5 years, $2-7$ & Psychometric, MRI & 2 & 13 & Invitation & $\begin{array}{l}\text { Age, sex, education, } \\
\text { socioeconomic status }\end{array}$ \\
\hline Brooks $^{\text {w16 }}$ & Case-control & Club, NA, 26 & Psychometric & 29 & 19 & Invitation & $\begin{array}{l}\text { Age, sex, education, } \\
\text { ethnicity }\end{array}$ \\
\hline Thomassen ${ }^{\text {w17 }}$ & Case-control & $\begin{array}{l}\text { Champions, NA, } 76 \\
\text { (median) }\end{array}$ & $\begin{array}{l}\text { Psychometric, EEG, } \\
\text { neurological }\end{array}$ & 53 & 53 & Invitation & $\begin{array}{l}\text { Age, sex, education, } \\
\text { occupation, }\end{array}$ \\
\hline Holzgrafe $^{\text {w18 }}$ & Case-series before-after & Top class, 2 months, 1 & MRI & 13 & 0 & Invitation & $\begin{array}{l}\text { Before and after (that is, act } \\
\text { as own controls) }\end{array}$ \\
\hline Jedlinskiw19 & Case-control & >100 bouts, NA, 153 & $\begin{array}{l}\text { Psychometric, EEG, } \\
\text { neurological }\end{array}$ & 60 & 30 & Invitation & $\begin{array}{l}\text { Reported as } \\
\text { "characterologic" }\end{array}$ \\
\hline Rodriguez $^{\mathrm{w} 20}$ & Case series & NS, NA, NS & $\begin{array}{l}\text { Regional cerebral blood } \\
\text { flow }\end{array}$ & 7 & 0 & invitation & NA \\
\hline McLatchie $^{\text {w21 }}$ & Case series & Club, NA, 4-200 & $\begin{array}{l}\text { Psychometric, CT, EEG, } \\
\text { neurological }\end{array}$ & 20 & 0 & Invitation & NA \\
\hline Ross $^{\text {w22 }}$ & Case series & Club, NA, $13-150$ & $\mathrm{CT}, \mathrm{EEG}$, neurological & 13 & 0 & Invitation & NA \\
\hline Jordan ${ }^{\text {w23 }}$ & Case series & NS, NA, NS & MRI, CT & 4 & 0 & Selected* & NA \\
\hline Legwold $^{\text {w24 }}$ & Case series & Military, NA, 4 & Neurological & 7000 & 0 & Compulsory & NA \\
\hline Jordan ${ }^{\text {w25 }}$ & Case series & Knockouts, NS, 13 & MRI, neurological & 9 & 0 & Selected & NA \\
\hline Casson $^{\mathrm{w} 26}$ & Case series & Club, NA, 0-80 & $\begin{array}{l}\text { Psychometric, CT, EEG, } \\
\text { neurological }\end{array}$ & 5 & 0 & Invitation & NA \\
\hline Kaste $^{\text {w27 }}$ & Case series & National, NA, 129 & $\begin{array}{l}\text { Psychometric, CT, EEG, } \\
\text { neurological }\end{array}$ & 8 & 0 & Invitation & NA \\
\hline Corsellis $^{\mathrm{w} 28}$ & Case series & $\begin{array}{l}\text { NS (postmortem study), NA, } \\
\text { NS }\end{array}$ & Histological & 3 & 0 & Selected† & NA \\
\hline Beaussart $^{\mathrm{w29}}$ & Case series before-after & NS, 1 bout, 1 & EEG, neurological & 123 & 0 & Invitation & $\begin{array}{l}\text { Before and after (that is, act } \\
\text { as own controls) }\end{array}$ \\
\hline Szymusik $^{\text {w30 }}$ & Case series & Long career, NA, >100 & EEG, neurological & 60 & 0 & Invitation & NA \\
\hline Moriyasuw31 & Case-control & NS, 1 bout, NS & EEG & 10 & 300 & NS & $\begin{array}{l}\text { Non-boxing head injury } \\
\text { patients }\end{array}$ \\
\hline Nesarajah $^{\text {w32 }}$ & Case-control & Mixed, NA, NS & EEG & 50 & 75 & Invitation & NS \\
\hline Beaussart $^{\mathrm{w33}}$ & Case series before-after & Club, 1 bout, 1 & EEG & 52 & 0 & NS & $\begin{array}{l}\text { Before and after (that is, act } \\
\text { as own controls) }\end{array}$ \\
\hline Blonstein $^{\text {w34 }}$ & Case series & Knockouts, NA, NS & EEG & 29 & NA & Selected & NA \\
\hline Pampus ${ }^{\text {w35 }}$ & Case series before-after & NS, NA, $1-4$ bouts & EEG, neurological & 207 & 0 & Selected & $\begin{array}{l}\text { Before and after (that is, act } \\
\text { as own controls) }\end{array}$ \\
\hline Blonstein ${ }^{\text {w36 }}$ & Case-control & Knockouts, 1 bout & EEG & 24 & 24 & Selected & Non-knockout boxers \\
\hline
\end{tabular}

EEG=electroencephalography; MRI=magnetic resonance imaging; $C T=c o m p u t e d$ tomography; SPECT=single photon emission computed tomography; Pt MOA=platelet monoamine oxidase inhibitor; NA=not applicable; NS=not stated.

* Selected on basis of referral to clinic with neurological problems.

†Selected on basis of dying in psychiatric hospital and having reportedly boxed at some time in life. 


\section{Psychometric testing}

Direct comparison between studies was confounded by the use of more than 20 different psychometric tests (up to 12 tests in a single study); however these tests give the highest quality evidence and were used in the four cohort studies ${ }^{\mathrm{w} 1 \mathrm{w} 2 \mathrm{w} 6 \mathrm{w} 15}$ and in two controlled before and after studies. ${ }^{\mathrm{w} 4 \mathrm{w} 9}$ The longer duration cohort studies found that, though there were differences from controls in baseline measurements in some psychometric tests (reflecting educational background), there was no longitudinal effect of boxing on psychometric testing, even at nine years. ${ }^{\mathrm{w} 1}$ Indeed in three studies, boxers out-performed controls on some tests. ${ }^{\mathrm{w} 1 \mathrm{w} 2 \mathrm{w} 6}$

Controlled before and after studies observed the acute effects of a boxing bout on performance, ${ }^{\mathrm{w} 4 \mathrm{w} 9}$ but the durations of altered results on psychometric assessment were not reported as boxers were not followed up long term. The positive findings in the smaller study ${ }^{\mathrm{w} 9}$ were not replicated in the later, larger study, which had a longer exposure and found no overall differences, ${ }^{\mathrm{w} 4}$ though a degree of association with exposure was present on subgroup analysis. One cohort study and two large well controlled series found an isolated abnormality of finger tapping in the non-dominant hand. ${ }^{\text {w12 w17 }}$ A further study with several positive findings used multivariate models to explore the effect of boxing on results of psychometric testing and introduced additional covariates to control for confounding factors. ${ }^{\text {w11 }}$ Although the case series had heterogeneous findings, a large well conducted, albeit uncontrolled, prospective study found no changes in results of psychometric tests from baseline over a two year period. ${ }^{\mathrm{w} 5}$

\section{Neuroimaging}

Imaging studies using contemporary techniquescomputed tomography, magnetic resonance imaging, SPECT (technetium-99m hexamethylpropyleneamineoxime single photon emission computed tomography), and isotope studies of cerebral blood flow (Xe133 CBF)_have built on earlier work using pneumoencephalography in professional boxers. ${ }^{14-16}$ Only one pneumoencephalographic study included an amateur boxer, who had the only normal results on encephalography. ${ }^{14}$ Though these studies provided the next best evidence after psychometric testing, the overall quality was poor with no cohort studies except that of Butler et al, ${ }^{\text {w }}$ who reported in the methods that $67 \%$ of the boxers underwent computed tomography but commented no further on this in the results or discussion.

Most of the other studies had small numbers of participants (often reflecting a selected subgroup of the whole study group). Most found no consistent abnormalities, and results correlated poorly with findings from other tests when used. For example, Kemp et al, despite identifying abnormalities both on psychometric testing and SPECT, showed no correlation between these findings. ${ }^{\text {w11 }}$ The highest positive yield from a case series was in seven of 13 boxers who underwent computed tomography, though the exact abnormalities were not described. ${ }^{\text {22 }}$ Other series found abnormalities in individual boxers who had competed in only seven and 14 bouts and were, at the time of study, aged 55 and 57, respectively. ${ }^{\text {w23 w26 }}$

\section{Electroencephalography and brain evoked potentials}

In the 1940s to 1960 s researchers extensively explored the potential of electroencephalography to indicate acute injury or chronic traumatic brain injury in amateur and professional boxers with variable results. ${ }^{14 \text { 17-19 }}$ Numerous early studies (case series and before and after studies) showed changes in the electroencephalogram in about half of boxers studied, w22 w24 w26 w27 w29 w31 33 w35 with more findings immediately after bouts, w33 w35 although these findings were not followed up longitudinally. Two recent case series found abnormal results on electroencephalography in about half of amateur boxers studied, although results were inversely correlated with advancing age and experience (more findings in younger subjects and with fewer bouts). ${ }^{\text {w24 w27 } \mathrm{A}}$ third found some abnormalities in three of 10 amateur boxers, ${ }^{\text {w22 }}$ though two were aged 14 and 16 and the other was aged 53 and all had normal results on psychometric testing, neurological examination, and computed tomography. While case-control studies from the 1960s observed more findings in boxers than controls, ${ }^{\text {w19 w32 }}$ these findings were in stark contrast to more recent case-control series and one prospective series that found no changes compared with controls $^{\mathrm{w} 5 \mathrm{w} 14 \mathrm{w17}}$ or from baseline function, ${ }^{\mathrm{w} 5}$ respectively.

\section{Clinical neurological examination}

There are several reports of clinical neurological abnormalities in small numbers of amateur boxers selected on the basis of evident symptoms or recorded acute neurological injury. ${ }^{141718}$ Nine case series that did not select, however, showed a wide variation in prevalence and severity ${ }^{\mathrm{w} 18 \text { w30 }}$ of findings (from none in 7000 boxers $^{\text {w24 }}$ to 33 of $60^{\text {w19 }}$ ). The widely cited study of McLatchie et al found that seven of 20 amateur boxers had abnormal results on neurological examination that correlated significantly $(\mathrm{P}<0.05)$ with increasing number of fights ${ }^{\mathrm{w} 21}$ (although we consider that the statistical method used to detect this, Mann-Whitney $\mathrm{U}$ test, was not appropriate). Other studies found no correlation with exposure or other methods of testing when used. $^{\text {w13w17w22 }}$ Of the three case-control $\mathrm{s}$ eries, two found that non-specific findings such as tremor, nystagmus, slurred speech, and fine movement abnormalities were similarly present in controls. $^{\text {w13w17 }}$ One large Polish study, however, found significant differences in the incidence of organic neurological dysfunction between high exposure group and controls or lower exposure groups. ${ }^{\text {w19 }}$

\section{Other outcomes}

In 1973 Corsellis presented evidence of histological changes in the brains of 15 boxers, of whom three were 
Table $3 \mid$ Results of included studies

\begin{tabular}{|c|c|c|c|c|}
\hline Reference & Outcome measure & Measure of effect & Results in exposed group $v$ controls (where applicable) & Result \\
\hline Porter ${ }^{\mathrm{w} 1}$ & Psychometric & Group comparison* & Better scores in $2 / 12$ tests $v$ controls & P<0.05 \\
\hline Porter $^{\mathrm{w} 2}$ & Psychometric & Group comparison* & Deterioration in finger tapping dominant hand (1/12 tests) & $P<0.01$ \\
\hline Zetterberg $^{\text {w3 }}$ & CSF biomarkers & Group comparison* & Increase in 3/6 CSF biomarkers $v$ controls and baseline (at rest) & $P=0.04 / 0.001$ \\
\hline Moriarty $^{\text {w4 }}$ & Psychometric & Group comparison $\dagger$ & Improvement in $1 / 5$ tests $v$ controls and baseline & $\mathrm{P}<0.05$ \\
\hline Stewart ${ }^{\mathrm{w} 5}$ & Psychometric & Odds ratio, contingency analysis & No differences in contingency or odds of abnormality with exposure & Not significant \\
\hline Stewart ${ }^{\mathrm{w} 5}$ & EEG & Odds ratio, contingency analysis & No differences in contingency or odds of abnormality with exposure & Not significant \\
\hline Stewart ${ }^{\mathrm{w} 5}$ & Brain evoked potentials & Odds ratio, contingency analysis & No differences in contingency or odds of abnormality with exposure & Not significant \\
\hline Butlerw6 $^{\text {w6 }}$ & Psychometric & Group comparison* & Improvements in $10 / 12$ tests from baseline & $P<0.01-0.001$ \\
\hline Haglund $^{\text {w7 }}$ & MRI & $\begin{array}{l}\text { Group comparisont, contingency } \\
\text { analysis }\end{array}$ & Small numbers of abnormalities in boxers and controls & Not stated \\
\hline Haglund $^{\text {w7 }}$ & CT & $\begin{array}{l}\text { Group comparisont, contingency } \\
\text { analysis }\end{array}$ & CSP in $2 / 47$ boxers $v 4 / 50$ controls, no group differences & Not stated \\
\hline Brayne $^{\text {w8 }}$ & Creatine kinase BB & Group comparison†, correlation & Significantly increased levels $v$ controls and with exposure & $\mathrm{P}<0.01, \mathrm{P}=0.05$ \\
\hline Master $^{\text {w9 }}$ & Psychometric & Group comparison* & Significant changes $v$ controls in $5 / 8$ tests used & $P<0.001-0.047$ \\
\hline Heilbronner $^{w 10}$ & Psychometric & Multivariate analysis & Significant changes, both positive (motor) and negative (memory) & $P<0.0001-0.004$ \\
\hline Kemp ${ }^{\text {w11 }}$ & Psychometric & Group comparison† & Significant difference $v$ controls in $4 / 5$ tests & P<0.05 \\
\hline Kemp ${ }^{\text {w11 }}$ & SPECT & Contingency analysis & $14 / 34$ boxers $v 5 / 34$ controls abnormal & P<0.02 \\
\hline Murelius $^{\text {w12 }}$ & Psychometric & Group comparison† & No significant difference except finger tapping (dominant hand). & P<0.001 \\
\hline Haglund ${ }^{\text {w13 }}$ & $\begin{array}{l}\text { Platelet monoamine } \\
\text { oxidase }\end{array}$ & Group comparison * & No difference between exposed group and controls & Not significant \\
\hline Haglund $^{\text {w13 }}$ & Neurological & Contingency analysis & $1 / 47$ boxers $v 3 / 50$ controls abnormal & Not significant \\
\hline Haglund $^{\text {w14 }}$ & EEG & Contingency analysis & No differences in contingencies of abnormalities & Not significant \\
\hline Haglund $^{\text {w14 }}$ & Brain evoked potentials & Group comparison† & No significant difference between exposed group and controls & Not significant \\
\hline Levin $^{\text {w15 }}$ & Psychometric & Multivariate analysis & Exposed group moved closer to control group results & $\mathrm{P}=0.10-0.89$ \\
\hline Levin $^{\text {w15 }}$ & MRI & NA & No abnormalities found in boxers (MRI not performed in controls) & NA \\
\hline Brooks $^{w 16}$ & Psychometric & Group comparison* & No evidence of neuropsychological abnormalities in boxers & Not significant \\
\hline Thomassen $^{\text {w17 }}$ & Psychometric & Multivariate analysis & No significant differences except finger tapping (dominant hand). & $\mathrm{P}<0.01$ \\
\hline Thomassen $^{\mathrm{w} 17}$ & EEG & Multivariate analysis & No significant difference between exposed and control group & Not significant \\
\hline Thomassen $^{\text {w17 }}$ & Neurological & Contingency analysis & "Sparse discrete" findings in boxers and controls & Not significant \\
\hline Holzgrafe $^{\text {w18 }}$ & MRI & Contingency analysis & $0 / 13$ abnormal before and after exposure & Not significant \\
\hline Jedlinskiw19 & Psychometric & Contingency analysis, correlation & $11 / 60$ abnormal $v 0 / 30$ controls, correlation with increasing bouts & Not stated, $r=0.50$ \\
\hline Jedlinskiw19 & EEG & Contingency analysis, correlation & $24 / 60$ abnormal v 2/30 controls, correlation with increasing bouts & Not stated, $r=0.50$ \\
\hline Jedlinskiw19 & Neurological & Contingency analysis, correlation & $33 / 60$ abnormal $v 3 / 30$ controls, correlation with increasing bouts & Not stated \\
\hline Rodriguez $^{\mathrm{w} 20}$ & $\begin{array}{l}\text { Regional cerebral blood } \\
\text { flow }\end{array}$ & NA & No abnormalities & NA \\
\hline McLatchie $^{\text {w21 }}$ & Psychometric & Group comparison* & $9 / 16$ abnormal, significant differences $v$ controls in $3 / 10$ tests & P<0.05 \\
\hline McLatchie $^{\text {w21 }}$ & CT & Correlation & $1 / 20$ abnormal in exposed group (dilated ventricles) & Not significant \\
\hline McLatchie $^{\text {w21 }}$ & EEG & Correlation & $8 / 20$ abnormal (various) correlating with increasing number of fights & P<0.05 \\
\hline McLatchie $^{\text {w21 }}$ & Neurological & Correlation & $7 / 20$ abnormal correlating with increasing number of fights & $\mathrm{P}<0.05$ \\
\hline Ross $^{\text {w22 }}$ & $\mathrm{CT}$ & NA & 7/13 abnormal (not specified) & NA \\
\hline Ross $^{\text {w22 }}$ & EEG & NA & 4/8 abnormal & NA \\
\hline Ross $^{\text {w22 }}$ & Neurological & NA & $1 / 8$ abnormal & NA \\
\hline Jordan $^{\text {w23 }}$ & MRI & NA & $1 / 4$ abnormal (congenital or post-traumatic cyst of hippocampus) & NA \\
\hline Jordan ${ }^{\text {w23 }}$ & $\mathrm{CT}$ & NA & $1 / 4$ abnormal (congenital or post-traumatic cyst of hippocampus) & NA \\
\hline Legwold $^{\text {w24 }}$ & Neurological & NA & 68 concussions/ 7000 bouts, none resulting in neurological dysfunction & NA \\
\hline Jordan ${ }^{\mathrm{w} 25}$ & MRI & NA & 0/9 abnormal & NA \\
\hline Jordan ${ }^{\mathrm{w} 25}$ & Neurological & NA & 0/9 abnormal & NA \\
\hline Casson $^{\text {w26 }}$ & Psychometric & NA & 2/5 abnormal as defined by "impairment index" & NA \\
\hline Casson $^{\text {w26 }}$ & CT & NA & $1 / 5$ abnormal (generalised cerebral atrophy) & NA \\
\hline Cassonw26 $^{\text {w2 }}$ & EEG & NA & $1 / 4$ abnormal & NA \\
\hline Casson $^{\text {w26 }}$ & Neurological & NA & 1/5 abnormal (mild "organic mental syndrome," right Babinsky) & NA \\
\hline Kaste $^{\text {w27 }}$ & Psychometric & NA & $0 / 8$ abnormal & NA \\
\hline Kaste $^{\text {w27 }}$ & $\mathrm{CT}$ & NA & $1 / 8$ abnormal & NA \\
\hline Kaste $^{\text {w27 }}$ & EEG & NA & 4/7 abnormal & NA \\
\hline Kaste $^{\text {w27 }}$ & Brain evoked potentials & NA & $1 / 7$ abnormal & NA \\
\hline Kaste $^{\text {w27 }}$ & Neurological & NA & $0 / 8$ abnormal & NA \\
\hline Corsellis $^{\text {w28 }}$ & Histological & NA & $0 / 3$ abnormal & NA \\
\hline
\end{tabular}




\begin{tabular}{|c|c|c|c|c|}
\hline Beaussart $^{w 29}$ & EEG & Contingency analysis & 0/123 abnormal (before $v$ after bout) & Not significant \\
\hline Szymusik $^{\mathrm{w} 30}$ & Neurological & NA & 6/60 abnormal ("boxer's encephalopathy") & NA \\
\hline Moriyasu $^{\text {w31 }}$ & EEG & NA & 2/10 abnormal ("slightly slow patterns") & NA \\
\hline Nesarajah $^{\text {w32 }}$ & EEG & Not stated & $30 / 50$ abnormal $v 6 / 75$ controls & Not stated \\
\hline Beaussart $^{\mathrm{w} 33}$ & EEG & Not stated & $25 / 52$ rhythm and slow posterior waves & Not stated \\
\hline Blonstein ${ }^{\text {w3 }}$ & EEG & NA & 0/29 abnormal & NA \\
\hline Blonstein ${ }^{\text {w34 }}$ & Neurological & NA & 0/29 abnormal & NA \\
\hline Pampus $^{\text {w5 }}$ & EEG & NA & $11 / 26$ abnormal after 3 bouts $v 34 / 116$ before any bouts & Not stated \\
\hline Pampus ${ }^{\mathrm{w} 35}$ & Neurological & NA & 42/175 abnormal & NA \\
\hline Blonstein $^{\text {w36 }}$ & EEG & NA & $4 / 24$ abnormal after bout but returned to normal rapidly & NA \\
\hline
\end{tabular}

amateur. ${ }^{\text {w28 }}$ Aside from possible flaws of attribution in this study (such as alcohol, syphilis, and head injuries from other causes) in association with positive findings in professional boxers, the authors concluded that no changes specific to boxing were present in the amateurs. Two studies examined neurochemical changes in the blood ${ }^{\mathrm{w} 8}$ and cerebrospinal fluid ${ }^{\mathrm{w} 3}$ of boxers after competition compared with athletic or non-athletic controls, respectively, and found significantly higher concentrations in boxers. In the latter studies each boxer underwent two lumbar punctures. ${ }^{\mathrm{w} 3}$ These increases were said to indicate disruption of the blood-brain barrier or acute neuronal and astroglial injury.

\section{DISCUSSION}

In this systematic review we found no evidence for a strong association between amateur boxing and chronic traumatic brain injury. In boxing the head might get hit repeatedly with resultant concussion, though less than in several more popular sportssuch as rugby union and equestrian activities ${ }^{3-5} 19$ which may harm cerebral function. Whether clinically measurable long term brain injury occurs is a different and more important question. There is reasonable clinical, ${ }^{814-16}$ radiological, ${ }^{14}{ }^{1520}$ and histopathological ${ }^{8172122 \text { w28 }}$ evidence that this is the case in a proportion of professional boxers $(10-20 \%$ in most studies), although most studies were performed at a time when safety standards were far less stringent than they are today. ${ }^{79}$

Amateur boxing is a different sport from professional boxing, including in its motivation to participate, rules, and equipment, but, most importantly, there is considerably greater exposure to injury in professionals (increased frequency and force of punches over a greater duration of career). ${ }^{9} \mathrm{We}$ looked at the data for chronic traumatic brain injury in amateur boxing alone. Although no formal synthesis was performed, the data can be described in summary. Overall, 15 of 36 studies $(42 \%)$ included in the systematic review concluded that relevant abnormalities were present, at least in a proportion of boxers studied. When we expressed this as a function of all methods tested (see table 3 ) we attained a similar figure (28/63, 44\%).

\section{Limitations}

It would clearly be impossible to perform a double blind randomised controlled trial for amateur boxing, though in general study design and conduct could have been greatly improved. Few studies were of sufficient quality to conclude anything other than a weak association when positive findings were reported, and none was sufficiently powered (no sample size calculations performed) to exclude a type II error when results were negative. Only two studies supplied confidence intervals for the main results. There was a definite tendency towards positive findings in studies of poorer quality and design. For instance, none of the four cohort

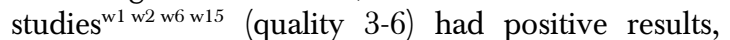
with three actually showing improvements over the study period. ${ }^{\mathrm{w} 1 \mathrm{w} 6 \mathrm{w} 15}$ This contrasts with the finding of abnormalities in over $50 \%$ of case series. With a cut-off of quality $\geq 3 / 6$, only four of $17(24 \%)$ studies and five of $26(20 \%)$ methods of testing yielded abnormal results. The latter is in contrast to studies that scored $\leq 2$ on quality, in which $62 \%$ (23/37) yielded positive results. Although perhaps not of importance, only two of 14 studies performed from 1990 onwards concluded that any measurable abnormality was present (and one of these was in a single boxer). The importance of using controls was illustrated by several case-control studies that showed that potentially severe abnormalities on clinical neurological examination ${ }^{\mathrm{w} 13 \mathrm{w} 17}$ as well as neuroimaging ${ }^{\mathrm{w} 7}$ were present equally in the control group.

\section{Bias}

Methods of selection were rarely adequately explained and occasionally performed on the basis of prior abnormal clinical or investigative findings. ${ }^{\text {w23 }}$ In terms of design, when controls were used these were poorly selected in terms of possible confounding factors. For instance, in one study that used psychometric tests, the controls (rugby and water polo players) were drawn from an undergraduate population, whereas many of the boxers had not completed their full time education. ${ }^{\mathrm{w} 6}$ As no data on IQ had been gathered this factor could not be assessed, and it is acknowledged that education and vocabulary have a large weighting on results of neuropsychometric 


\section{WHAT IS ALREADY KNOWN ON THIS TOPIC}

The safety of amateur boxing in terms of risk of chronic traumatic brain injury continues to be questioned

No recent or systematic review has been performed to assess the evidence for this

\section{WHAT THIS STUDY ADDS}

A systematic review of observational studies indicates that, although the quality of evidence supporting or refuting the hypothesis was poor, the association between amateur boxing and chronic traumatic brain injury is not strong

testing. In respect of performance, remarkably in only two studies were observers blinded. ${ }^{\text {w1 }}{ }^{\text {w1 } 12}$ Finally, though we did not carry out a formal analysis of publication bias, studies showing adverse effects might have been more likely to get published.

In studies that sought an association between exposure and outcome, few found an effect, raising the question of false attribution. Indeed, questions of specificity exist for almost all methods used. In psychometric testing, three well conducted studies found a single significant difference in the finger tapping test of the non-dominant hand. ${ }^{\mathrm{w} 2 \mathrm{w} 12 \mathrm{w} 17}$ This finding has been replicated in other studies and seems to be worse with increased exposure to boxing. The association between finger tapping response and brain damage is difficult to assess in boxers, however, given the chronic damage to the fingers directly associated with repeated punches. ${ }^{\text {w1223 }}$ The observation in electroencephalography studies of an inverse association between exposure or age and positive findings ${ }^{\mathrm{w} 21 \mathrm{w} 27}$ might similarly be explained by the recognised false positive rate of electroencephalography, particularly in the young. ${ }^{24}$ The problems implicit in analysis are also illustrated by the revision of findings (from highly significant to zero) by a single group in two consecutive publications. $^{\text {w29 w33 }}$ Imaging methods have similar inherent difficulties of interpretation with the relevance of some much championed findings, such as cavum septum pellucidum and ventricular abnormalities, ${ }^{15171825}$ questioned by others. ${ }^{26-28}$ This issue is well reviewed elsewhere,${ }^{26}$ and the relevance of many of these abnormalities remains dubious. In respect of blood concentrations of creatine kinase $\mathrm{BB}$, increased levels have also been observed in oarsmen and marathon runners. ${ }^{29}$ When, as in some series, participants in their $50 \mathrm{~s}$ were described with clinical neurological abnormalities after a limited exposure (as few as seven bouts) some 30 years previously, ${ }^{\text {w24 w27 }}$ the sole attribution of these findings to boxing must surely be questioned.

Conversely, the current range of tests might lack sensitivity to detect subtle changes in neural structure or function. All these tests must be regarded as surrogate markers for the notional concept of chronic traumatic brain injury and clearly no conclusion can be reached on this without an ideal test for comparison or indeed a clear definition of what might constitute clinically relevant injury. Nevertheless, tests regarded as sensitive in general neurological practice have all been used. In particular, psychometric testing, regarded by some as the most sensitive, ${ }^{\text {w2123 }}{ }^{2}$ provided the most conclusive negative results. ${ }^{\mathrm{w} 1 \mathrm{w} 2 \mathrm{w} 4}$ 6 w15 Similarly, it is generally accepted that magnetic resonance imaging is the best method of determining subtle parenchymal damage and degenerative change. In the six studies that used this, only one case series of four boxers concluded that relevant abnormality was present. This was a cyst in a single boxer, which was possibly congenital. ${ }^{\text {w23 }}$ No abnormalities were found in the single cohort study that used magnetic resonance imaging. ${ }^{\mathrm{w} 15}$

Finally, because of the short duration or "snapshot" design of nearly all studies (except that of longer follow-up cohort studies in which no detrimental effects were found ${ }^{\mathrm{w} 1 \mathrm{w} 2 \mathrm{w} 5}$ ), it is impossible to conclude whether or not longer exposure would have eventually led to chronic injury or whether such changes might present in much later life when further neuronal loss occurs with ageing. Implicit within this latter argument is the possibility that subclinical, sub-psychometric, and sub-radiological brain damage incurred as an amateur may contribute to that which becomes clinically evident in those who subsequently have a long professional boxing career. This was not, however, indicated by findings at nine year follow-up. ${ }^{\mathrm{w} 1}$

\section{Conclusions}

Amateur boxing is becoming an increasingly popular participation sport, especially within universities and for both sexes. The safety of boxing is an issue that stimulates emotive responses on both sides of the debate, and calls to ban the sport continue. This review neither seeks to endorse nor oppose the sport of amateur boxing. It is perhaps a question of personal philosophy whether it is incumbent on boxing to prove that it is safe, or on those who oppose it to prove that it is deleterious (although it might be argued that those wanting to alter the status quo have the responsibility to prove this). Nevertheless, on the basis of this systematic review, we conclude that the current evidence, such as it exists, for chronic traumatic brain injury as a consequence of amateur boxing is not strong.

Contributors: ML and CK made substantial contributions to conception and design of the study, acquisition, analysis, and interpretation of data, and drafting and revising the article. GW critically revised the article for important intellectual content. All authors gave final approval of the version to be published. ML is guarantor.

Funding: None.

Competing interests: ML is lead sports physician (London Region) at the English Institute of Sport, Olympic Medical Institute, and physician to the British Amateur Boxing Team. ML and CK are commissioners on the ABA of England Medical Commission

Ethical approval: Not required.

Provenance and peer review: Not commissioned; externally peer reviewed.

1 British Medical Association. The boxing debate. London: Chameleon Press, 1993.

2 BMA Board of Science Working Party on Boxing. Second report 2007. www.bma.org.uk/ap.nsf/Content/BoxingPU. 
3 Finch C, Da Costa A, Stevenson M, Hamer P, Elliott B. Sport injury experiences from the Western Australian sports injury cohort study. Aust N ZJ Public Health 2002;26:462-7.

4 Clark KS. Epidemiology of athletic head injury. Clin Sports Med 1998;17:1-12.

5 Zazyrn T, Cameron P, McCrory P. A prospective cohort study of injury in amateur and professional boxing. Br J Sports Med 2006;40:670-4.

6 Blonstein JL, Medical aspects of amateur boxing. Proc R Soc Med 1966;59:649-52.

7 Clausen $\mathrm{H}, \mathrm{McC}$ rory P, Anderson V. The risk of chronic traumatic brain injury in professional boxing: change in exposure variables over the past century. Br J Sports Med 2005;39:661-4.

8 Martland HS. "Punch drunk." JAMA 1928;91:1103-7.

9 McCrory P, Zazryn T, Cameron P. The evidence for chronic traumatic encephalopathy in boxing. Sports Med 2007;37:467-76.

10 Moher D, Cook DJ, Eastwood S, Olkin I, Rennie D, Stroup DF, for the QUOROM Group. Improving the quality of reports of meta-analyses of randomised controlled trials: the QUOROM statement. Lancet 1999;354:1896-900.

11 Stroup DF, Berlin JA, Morton SC, Olkin I, Williamson GD, Rennie D, et al. Meta-analysis of observational studies in epidemiology: a proposal for reporting. JAMA 2000;283:2008-12.

12 Khan K, ter Riet G, Popay J, Nixon J, Kleijnen J, eds. Undertaking systematic reviews of research on effectiveness. York: University of York, 2001. (CRD Report No 4.) www.york.ac.uk/inst/crd/report4. htm.

13 Cabanis EA, Perez G, Tamraz JC, Iba-Zizen MT, Roger B, Alfonzo JM, et al. Cephalic magnetic resonance imaging of boxers. Preliminary results. Acta Radiol Suppl 1986;369:365-6.

14 Mawsdley C, Ferguson FR. Neurological disease in boxers. Lancet 1963;ii:795-801.

15 Spillane JD. Five boxers. BMJ 1962;ii:1205-10.

16 Roberts AJ. Brain damage in boxers. London: Pitman Medical Scientific Publications, 1969.
17 Critchley M. Medical aspects of boxing, particularly from neurological standpoint. BMJ 1957;i:357-62.

18 Unterharnscheidt F, Sellier K. Boxing. Mechanics, pathomorphology and clinical picture of traumatic lesions of the CNS in boxers. Fortschr Neurol Psychiatr Grenzgeb 1971;39:109-51 (in German).

19 Toth C, McNeil S, Feasby T. Central nervous system injuries in sport and recreation: a systemic review. Sports Med 2005;35:685-718.

20 Jordan BD, Jahre C, Hauser WA, Zimmerman RD, Zarrelli M, Lipsitz EC, et al. CT of 338 active professional boxers. Radiology 1992;185:509-12.

21 Jordan BD. Chronic traumatic brain injury associated with boxing Semin Neurol 2000;20:179-85

22 Roberts GW, Allsop D, Bruton C. The occult aftermath of boxing. Neurol Neurosurg Psychiatry 1990;53:373-8.

23 Butler RJ. Neuropsychological investigation of amateur boxers. $\mathrm{Br}$ J Sports Med 1994;4:28

24 Gibbs FA, Gibbs EL. Atlas of electroencephlopathy, 2nd ed. Reading MA: Addison-Wesley, 1958;1:324.

25 Bogdanoff B, Natter HM. Incidence of cavum septum pellucidum in adults: a sign of boxers encephalopathy. Neurology 1989;87:535-605

26 Moseley IF. The neuroimaging evidence for chronic brain damage due to boxing. Neuroradiology 2000;42:1-8.

27 McCrory P. Carvum septum pellucidi-a reason to ban boxers? Br J Sports Med 2002;36:157-61.

28 Macpherson P, Teasdale E. CT demonstration of a 5th ventricle-a finding to KO boxers? Neuroradiology 1988;30:506-10.

29 Phillips J, Horner B, Ohman M, Horgan J. Increased brain-type creatine phosphokinase in marathon runners. Lancet 1982;i:1310.

30 Grindel SH, Lovell MR, Collins MW. The assessment of sports-related concussion: the evidence behind neuropsychological testing and management. Clin J Sports Med 2001;11:134-43

Accepted: 7 August 2007 